\title{
Qualidade microbiológica e suscetibilidade antimicrobiana do leite in natura comercializado em Cruz das Almas, Bahia
}

\author{
Microbiological quality and antimicrobial susceptibility of \\ informally traded milk in Cruz das Almas county, Bahia
}

\author{
Norma Suely Evangelista Barreto ${ }^{*}$; Gleyde Córdova da França Santos²; \\ Aura Lacerda Crepaldi ${ }^{3}$; Rebeca Ayala Rosa dos Santos ${ }^{4}$
}

\section{Resumo}

\begin{abstract}
Para a avaliação da qualidade microbiológica do leite in natura, bem como a suscetibilidade antimicrobiana das bactérias isoladas, foram analisados 25 estabelecimentos comerciais em Cruz das Almas, Ba. Para isso realizou-se a quantificação de micro-organismos heterotróficos mesófilos e psicrotróficos aeróbios, bolores e leveduras, Staphylococcus spp., Staphylococcus coagulase positiva, coliformes $\left(35^{\circ} \mathrm{C}\right.$ e $\left.45^{\circ} \mathrm{C}\right)$ e presença de Salmonella spp. e Escherichia coli. A contagem média de micro-organismos heterotróficos mesófilos foi de $1,6 \times 10^{9} \mathrm{UFC}_{\mathrm{mL}}^{-1}$, psicrotróficos $9,6 \times 10^{4} \mathrm{UFC}$. $\mathrm{mL}^{-1}$, bolores e leveduras $3,8 \times 10^{8} \mathrm{UFC} \cdot \mathrm{mL}^{-1}$, coliformes a $35^{\circ} \mathrm{C} 4 \times 10^{5} \mathrm{NMP} \cdot \mathrm{mL}^{-1}$ e a $45^{\circ} \mathrm{C} 3,8 \times$ $10^{5} \mathrm{NMP} . \mathrm{mL}^{-1}$. Staphylococcus coagulase positiva foi observada em $44 \%$ das amostras, com média de $7,3 \times 10^{5}$ UFC. $\mathrm{mL}^{-1}$ e diferença estatística $(\mathrm{P}>0,05)$ entre os estabelecimentos. Escherichia coli foi isolada em $76 \%$ das amostras, e a presença de Salmonella não foi observada em nenhuma das amostras. Escherichia coli apresentou resistência à tetraciclina (57,9\%), ampicilina e cloranfenicol $(10,5 \%)$ e cefalotina (5,3\%), enquanto as estirpes de Staphylococcus coagulase positivo foram resistentes a amicacina (18\%) e vancomicina (18\%). O leite in natura, além de apresentar qualidade microbiológica insatisfatória, colocando em risco a saúde dos consumidores, pode servir de veículo de disseminação de bactérias resistentes a diferentes agentes antimicrobianos.
\end{abstract}

Palavras-chave: Escherichia coli, toxiinfecção alimentar, patógenos, segurança alimentar

\begin{abstract}
The microbiological quality as well as the antimicrobial susceptibility of bacteria isolated from raw milk obtained from 25 food stores in Cruz das Almas, Bahia were evaluated. The analysis included counts of mesophilic and psicrotrophic microorganisms, molds and yeast, Staphylococcus spp., coagulase-positive Staphylococcus, coliforms (at $35^{\circ} \mathrm{C}$ and $45^{\circ} \mathrm{C}$ ), and the presence of Salmonella spp. and Escherichia coli. The average count for mesophilic and psicrotrophic microorganisms, molds and yeast, and coliforms at $35^{\circ} \mathrm{C}$ and $45^{\circ} \mathrm{C}$ were $1.6 \times 10^{9} \mathrm{CFU} \cdot \mathrm{mL}^{-1}, 9.6 \times 10^{4} \mathrm{CFU} \cdot \mathrm{mL}^{-1}, 3.8 \times 10^{8} \mathrm{CFU}$. $\mathrm{mL}^{-1}, 4.0 \times 10^{5} \mathrm{MPN} \cdot \mathrm{mL}^{-1}$ and $3.8 \times 10^{5} \mathrm{MPN} \cdot \mathrm{mL}^{-1}$, respectively. Coagulase positive Staphylococcus was found in $44 \%$ of the samples (mean value of $7.3 \times 10^{5}$ CFU.mL ${ }^{-1}$ ), and E. coli was present in $76 \%$ of them. Salmonella was not detected in any of the samples tested. E. coli showed resistance (57.9\%) to tetracycline, to ampicillin and chloramphenicol (10.5\%), and cephalotin (5.3\%), while coagulase-
\end{abstract}

\footnotetext{
${ }^{1}$ Prof $^{\mathrm{a}}$. Pesquisadora do Programa de Mestrado em Microbiologia Agrícola, Universidade Federal do Recôncavo da Bahia, UFRB, Cruz das Almas, BA. E-mail: nsevangelista@ufrb.edu.br

${ }^{2}$ Discente do Programa de Mestrado em Microbiologia Agrícola, UFRB, Cruz das Almas, BA. E-mail: gleydecordova@hotmail. com

${ }^{3}$ Discente do curso de Engenharia de Pesca, UFRB, Cruz das Almas, BA. E-mail: a_crepaldi@hotmail.com

${ }^{4}$ Discente do curso de Ciências Biológicas, UFRB, Cruz das Almas, BA. E-mail: rebeca_rosa@yahoo.com.br

* Autor para correspondência
} 
positive Staphylococcus strains were resistant to amicacin (18\%) and vancomicin (18\%). The raw milk besides to present poor microbiological quality, becoming a health risk of the consumers, it may contribute to the dissemination of resistant bacteria to various antimicrobial agents.

Key words: Escherichia coli, food poisoning, pathogens, food security

\section{Introdução}

Em 2011, o Brasil produziu 32,1 bilhões de litros de leite fluido, sendo que aproximadamente, 33\% deste volume tratou-se de leite não inspecionado (EMBRAPA, 2012). O destino do leite sem inspeção é o mercado informal, podendo ser vendido diretamente ao consumidor ou ser comercializado na forma de derivados produzidos por pequenos laticínios (MACIEL et al., 2008).

A baixa qualidade microbiológica encontrada no leite in natura produzido no Brasil é reflexo das precárias condições de higiene típicas da produção nacional. Embora importantes para a economia do país, as fazendas leiteiras ainda apresentam pouco ou nenhum conhecimento tecnológico, com condições higiênicas insatisfatórias e controle sanitário ineficiente (ARCURI et al., 2006; NERO; VIÇOSA; PEREIRA, 2009).

O consumo de leite sem tratamento prévio, como a pasteurização, expõe a população a diversas doenças como a tuberculose e a brucelose (GERMANO; GERMANO, 2008), além de não assegurar a distribuição de um produto inócuo. Para ser considerado de qualidade, o leite precisa ter qualidade sensorial, nutricional e físico-química, bem como contagem reduzida de células somáticas e baixa carga microbiana (ZOCCHE et al., 2002). Por outro lado, outro problema enfrentado com o consumo de leite diz respeito à presença de resíduos de antibióticos, pois além de desencadear fenômenos alérgicos em indivíduos sensíveis promove alterações no equilíbrio da flora intestinal e a seleção de bactérias resistentes no trato digestório dos consumidores, possibilitando o surgimento de multiressitência aos antimicrobianos pelos microorganismos, dificultando o tratamento de doenças consideradas comuns (ALMEIDA et al., 2003).
Entre os indicadores mais utilizados para a qualidade higiênica sanitária dos alimentos, destacam-se o grupo dos coliformes e Staphylococcus coagulase positiva. Os coliformes são indicadores de contaminação fecal e do risco da presença de micro-organismos patogênicos, como a Salmonella. Os estafilococos são de grande importância, principalmente os coagulase-positiva, pois podem produzir enterotoxinas termoestáveis, atingindo o consumidor mesmo após o processo de pasteurização (MACIEL et al., 2008). A contagem de micro-organismos mesófilos é contemplada na legislação brasileira para leite in natura (BRASIL, 2011). Entretanto, muitas dessas normas não são seguidas, e uma das principais justificativas para a quantificação desse grupo de bactérias é que todas as bactérias patogênicas de origem alimentar são mesófilas (FRANCO; LANDGRAF, 2008).

Apesar da comercialização do leite in natura ser considerada proibida pelos órgãos federais, em Cruz das Almas (BA) sabe-se que alguns estabelecimentos ainda comercializam esse alimento em virtude da elevada procura. Este fato se deve a crença popular de que esse leite é mais rico em nutrientes. Por outro lado, o baixo custo estimula seu consumo principalmente pela população de baixa renda. Diante do exposto, o objetivo deste estudo foi avaliar a qualidade microbiológica do leite in natura comercializado no município de Cruz das Almas, Bahia, visando verificar as características sanitárias do produto, bem como a suscetibilidade das estirpes isoladas a diferentes agentes antimicrobianos comerciais.

\section{Material e Métodos}

No período de abril a setembro de 2010 foram analisados 25 estabelecimentos que comercializavam 
leite in natura em Cruz das Almas, Bahia. Os estabelecimentos foram divididos de acordo com a sua atividade comercial (04 açougues, 08 padarias, 08 mini-mercados e 05 supermercados). As amostras de leite foram adquiridas em volume de 1 L e encaminhadas ao Laboratório de Microbiologia de Alimentos e Ambiental, no Núcleo de Estudos em Pesca e Aqüicultura (NEPA) na Universidade Federal do Recôncavo da Bahia (UFRB) para a quantificação de bactérias heterotróficas mesófilas e psicrotróficas aeróbias, bolores e leveduras, coliformes a $35^{\circ} \mathrm{C}$ e a $45^{\circ} \mathrm{C}$, Staphylococcus spp., Staphylococcus coagulase positiva, bem como a presença de Escherichia coli e Salmonella.

Para a contagem das bactérias heterotróficas mesófilas e psicrotróficas aeróbias, adicionou-se uma alíquota de $25 \mathrm{~mL}$ da amostra em $225 \mathrm{~mL}$ de solução salina a $0,85 \%$ de $\mathrm{NaCl}$, homogeneizada e, a partir desta, realizadas diluições seriadas até $10^{-}$ 5. Em seguida, alíquotas de $1 \mathrm{~mL}$ foram semeadas em duplicata em placas de Petri, contendo o meio Plate Count Agar (PCA) usando a técnica de pour plate para as bactérias heterotróficas mesófilas e de spread plate para os psicrotróficos. As placas foram incubadas a $35^{\circ} \mathrm{C} / 24-48 \mathrm{~h}$ para os mesófilos e a $7^{\circ} \mathrm{C}$ por até 10 dias para os psicrotróficos. Na contagem de bolores e leveduras, alíquotas de $0,1 \mathrm{~mL}$ foram semeadas na superfície do meio Ágar Sabouraud Dextrose a 4\% suplementado com cloranfenicol e incubado a $25^{\circ} \mathrm{C} \pm 1$ por cinco a sete dias (SILVA et al., 2007).

A determinação de coliformes a $35^{\circ} \mathrm{C}$ e a $45^{\circ} \mathrm{C}$ foi realizada usando a técnica de fermentação dos tubos múltiplos (Número Mais Provável - NMP. $\left.\mathrm{mL}^{-1}\right)$. Inicialmente alíquotas de $1 \mathrm{~mL}$ da amostra foram inoculadas em Caldo Lauril Sulfato Triptose (CLS) contendo tubos de Durhan invertidos e incubados a $35^{\circ} \mathrm{C} / 48 \mathrm{~h}$. Os tubos que apresentaram turvação do meio e formação de gás nos tubos de Durhan uma nova alíquota foi transferida para tubos contendo Caldo Lactose Bile Verde Brilhante (CBVB) e caldo Escherichia coli (EC) e incubados respectivamente, a $35^{\circ} \mathrm{C} / 48 \mathrm{~h}$ e a $45^{\circ} \mathrm{C} / 24 \mathrm{~h}$, em banho-maria. Decorrido esse período, os tubos EC positivos foram semeados no meio Agar Eosina Azul de Metileno (EMB) e incubados a $35^{\circ} \mathrm{C} / 24 \mathrm{~h}$. As colônias características de $E$. coli foram isoladas em tubos de ensaio contendo Agar Triptose Soja (TSA) e submetidas aos testes bioquímicos do IMViC (indol, vermelho de metila, voges-proskauer e citrato de Simmons) (SILVA et al., 2007).

A contagem de Staphylococcus spp. e Staphylococcus coagulase positiva foi realizada por spread plate usando alça de Drigalski. Inoculouse $0,1 \mathrm{~mL}$ da amostra em Agar Baird-Parker, em duplicata, e incubou-se a $35^{\circ} \mathrm{C} / 48 \mathrm{~h}$. Em seguida, foi realizada a contagem do número de colônias que apresentavam características típicas, ou seja, colônias negras, circulares, brilhantes, pequenas, lisas, convexas, com bordas perfeitas e rodeadas por uma zona opaca e/ou halo transparente. O número de colônias contadas foi multiplicado pelo fator 10 e a diluição correspondente. As colônias características de Staphylococcus foram submetidas aos testes de catalase e coagulase (SILVA et al., 2007).

Para a pesquisa de Salmonella, inicialmente realizou-se o pré enriquecimento adicionando 25 $\mathrm{mL}$ da amostra em $225 \mathrm{~mL}$ de Caldo Lactose (CL) e incubado a $35^{\circ} \mathrm{C} / 24 \mathrm{~h}$. Em seguida, alíquotas de $1 \mathrm{~mL}$ e $0,1 \mathrm{~mL}$ foram inoculadas em $10 \mathrm{~mL}$ de caldo Tetrationato (TT) e caldo Rappaport (RV), respectivamente e incubados a $37^{\circ} \mathrm{C} / 24 \mathrm{~h}$ e $42^{\circ} \mathrm{C} / 24$ $\mathrm{h}$, em banho-maria. Posteriormente alíquotas foram retiradas e estriadas nos meios seletivos Agar MacConkey (colônias incolores ou translucidas levemente amareladas) Agar Salmonella-Shigella (colônias com ou sem centro negro) e Agar Verde Brilhante (colônias róseas a vermelhas) e incubadas a $35^{\circ} \mathrm{C} / 24 \mathrm{~h}$. As colônias com morfologia característica de Salmonella foram inoculadas em Agar Ferro Açúcar Triplo (TSI) e Agar Lisina Ferro (LIA) e incubados a $35^{\circ} \mathrm{C} / 24 \mathrm{~h}$. A partir do crescimento positivo (ácido na base e alcalino no ápice para Agar TSI e alcalino com ou sem produção de gás para LIA) uma nova alíquota foi retirada e semeada em Agar Tripitona Soja (TSA), 
para posterior identificação bioquímica (urease, indol, fermentação de dulcitol, sacarose e lactose, vermelho de metila (VM), voges-proskauer (VP), utilização do citrato e descarboxilação da lisina) e teste sorológico (SILVA et al., 2007).

Para o teste de antibiograma o método utilizado seguiu as recomendações do Clinical and Laboratory Standards Institute - CLSI (CLSI, 2005). Para o teste foram usadas 19 cepas de $E$. coli e 11 de Staphylococcus coagulase positiva. Para a padronização do inoculo, mediu-se a densidade óptica da cultura, em espectrofotômetro, no comprimento de onda de $625 \mathrm{~nm}$, com base na escala de MacFarland a 0,5 $\left(10^{7}-10^{8}\right.$ UFC.mL $\left.L^{-1}\right)$. Após o ajuste do inóculo, mergulhava-se um $s w a b$ de algodão estéril na salina turva, pressionando-o firmemente contra a parede interna do tubo a fim de ser retirado o excesso e semeados em placas contendo Agar Muller-Hinton. Em seguida, os discos dos antimicrobianos foram depositados nas placas e estas, incubadas a $37^{\circ} \mathrm{C} / 18 \mathrm{~h}$. A medição dos halos de inibição foram medidos em milímetros com o uso de paquímetro digital. Para os testes de sensibilidade foram selecionados 12 antimicrobianos comerciais: ácido nalidíxico - NAL (30 $\mu \mathrm{g})$, ampicilina - AMP $(10 \mu \mathrm{g})$, ceftazidime - CFZ $(30 \mu \mathrm{g})$, cloranfenicol - CLO $(30 \mu \mathrm{g})$, gentamicina - GEN (100 $\mu \mathrm{g})$, imipenem - IPM $(10 \mu \mathrm{g})$, sulfazotrin - SUT $(25 \mu \mathrm{g})$, tetraciclina - TET $(30 \mu \mathrm{g})$, nitrofurantoina - NIT $(300 \mu \mathrm{g})$, amicacina - AMI $(30 \mu \mathrm{g})$, cefalotina $-\mathrm{CFL}$ $(30 \mu \mathrm{g})$, ciprofloxacino - CIP $(5 \mu \mathrm{g})$ e vancomicina - VAN $(30 \mu \mathrm{g})$. Como controle utilizou-se uma cepa de referência Escherichia coli ATCC 25922 e Staphylococcus aureus ATCC 25923.

A presença ou ausência de plasmídios- $\mathrm{R}$ foi testada para as estirpes que apresentaram perfil de multi-resistência aos antimicrobianos testados. Como agente de cura foi utilizado o Acridine Orange (AO) na concentração de $100 \mu \mathrm{g} / \mathrm{mL}$. As cepas foram crescidas em caldo Luria-Bertani (LB) $+\mathrm{AO}$ e incubadas a $30^{\circ} \mathrm{C} / 24 \mathrm{~h}$. Após esse período realizou-se novamente o antibiograma a fim de verificar se houve alteração no perfil de resistência aos antimicrobianos previamente testados (MOLINA-AJA et al., 2002).

$\mathrm{O}$ índice MAR (múltipla resistência antimicrobiana) foi utilizado para determinação da múltipla resistência dos micro-organismos. Este índice é definido como a/b, ou seja, o número de antimicrobianos aos quais o isolado foi resistente (a), dividido pelo número de antimicrobianos aos quais o isolado foi exposto (b), multiplicando-se o valor final por 100 para obtenção dos resultados em percentual (HIRSCH et al., 2006).

Delineamento inteiramente casualizado (DIC) foi usado utilizando os estabelecimentos como tratamento e as amostragens como repetição, sendo o estabelecimento 01 (açougues), 02 (padarias), 03 (mini-mercados) e 04 (supermercados). Os resultados foram submetidos à Análise de variância (ANOVA) por meio do programa Sisvar 5.1. Utilizou-se o teste de Tukey ao nível de 5\% de significância.

\section{Resultados e Discussão}

Foi observada elevada contagem microbiana em todas as amostras analisadas, independente do estabelecimento obtido. Apesar dos açougues apresentarem as piores condições higiênicas, situação observada visualmente durante a obtenção das amostras, o leite não apresentou as maiores contaminações. A contagem de bactérias heterotróficas mesófilas variou de $9,1 \times 10^{5}$ a 8,8 $\times 10^{9}$ UFC. $\mathrm{mL}^{-1}$. Apesar dos micro-organismos mesófilos nas amostras provenientes dos supermercados terem apresentado maior contaminação, não houve diferença significativa entre os estabelecimentos $(p<0,05)$ (Tabela 1). Todas as amostras estavam fora dos padrões estabelecidos pela Instrução Normativa 62 (BRASIL, 2011) que limita valores de 1,0 x $10^{4}$ UFC. $\mathrm{mL}^{-1}$ para leite cru refrigerado tipo A integral. O grupo de micro-organismos heterotróficos mesófilos inclui a maioria das bactérias acidificantes do leite e os patógenos (FRANCO; LANDGRAF, 2008). Melo et al. (2010) relataram contagens de 
$1,8 \times 10^{5}$ a $2,2 \times 10^{6}$ UFC.ml ${ }^{-1}$ no leite in natura comercializado no município de Major Isidoro, Alagoas. Alves et al. (2009) encontraram contagens de mesófilos na faixa $10^{5}$ a $10^{7}$ UFC.mL $\mathrm{mL}^{-1}$ no leite comercializado informalmente na cidade de São Luís-MA, enquanto Schedler et al. (2009) relataram contagens de $3,90 \times 10^{6}$ UFC. $\mathrm{mL}^{-1}$ em diferentes propriedades do oeste paranaense. Santana et al. (2001) relataram redução nos valores de mesófilos e psicrotróficos de $86 \%$ e $96 \%$ respectivamente, após a higienização dos tetos, demonstrando que grande porcentagem de micro-organismos dos tetos dos animais são incorporados no leite.

Tabela 1. Valores médios das contagens microbianas no leite in natura obtido em diferentes estabelecimentos em Cruz das Almas, Bahia, durante o período de abril a setembro de 2010.

\begin{tabular}{ccccccc}
\hline \multirow{2}{*}{$\begin{array}{c}\text { Estabelecimentos } \\
\text { (número) }\end{array}$} & Mesófilos & Psicrotróficos & $\begin{array}{c}\text { Bolores e } \\
\text { Leveduras }\end{array}$ & $\begin{array}{c}\text { Coliformes } \\
\mathbf{a ~ 3 5} \mathbf{3 5}^{\circ} \mathbf{C}\end{array}$ & $\begin{array}{c}\text { Coliformes } \\
\mathbf{a} \mathbf{4 5}^{\circ} \mathbf{C}\end{array}$ & $\begin{array}{c}\text { Staphylococcus } \\
\text { coagulase } \\
\text { positiva }\end{array}$ \\
\hline $01(\mathrm{n}=4)$ & $9,5 \times 10^{7} \mathrm{a}$ & $1,5 \times 10^{3} \mathrm{a}$ & $1,5 \times 10^{7} \mathrm{a}$ & $1,3 \times 10^{4} \mathrm{~b}$ & $2,8 \times 10^{5} \mathrm{a}$ & $2,9 \times 10^{6} \mathrm{a}$ \\
$02(\mathrm{n}=8)$ & $1,8 \times 10^{9} \mathrm{a}$ & $2,6 \times 10^{5} \mathrm{a}$ & $9,4 \times 10^{8} \mathrm{a}$ & $8,6 \times 10^{5} \mathrm{a}$ & $1,0 \times 10^{6} \mathrm{a}$ & $5,9 \times 10^{4} \mathrm{~b}$ \\
$03(\mathrm{n}=8)$ & $1,6 \times 10^{9} \mathrm{a}$ & $3,8 \times 10^{4} \mathrm{a}$ & $1,1 \times 10^{8} \mathrm{a}$ & $2,4 \times 10^{5} \mathrm{ab}$ & $2,0 \times 10^{4} \mathrm{a}$ & $3,9 \times 10^{3} \mathrm{~b}$ \\
$04(\mathrm{n}=5)$ & $2,9 \times 10^{9} \mathrm{a}$ & $8,7 \times 10^{4} \mathrm{a}$ & $4,7 \times 10^{8} \mathrm{a}$ & $4,9 \times 10^{5} \mathrm{ab}$ & $1,9 \times 10^{5} \mathrm{a}$ & $4,7 \times 10^{3} \mathrm{~b}$ \\
\hline
\end{tabular}

Obs: Médias na mesma coluna seguidas de letras diferentes apresentam diferença estatística pelo teste de Tukey $(\mathrm{P}<0,05)$. Estabelecimentos 01 - açougue; 02 - padaria; 03 - mini-mercados e 04 - supermercados.

$\mathrm{UFC}=$ Unidades Formadoras de Colônias. NMP = Número Mais Provável.

Fonte: Elaboração dos autores.

A presença de bactérias psicrotróficas foi observada em $80 \%$ das amostras de leite, com contagens variando de 9,5 × $10^{2}$ a 1,5 × $10^{6}$ UFC. $\mathrm{mL}^{-1}$. As amostras obtidas nas padarias apresentaram maior média microbiana $\left(2,6 \times 10^{5}\right.$ UFC.mL $L^{-1}$, embora sem diferença significativa $(\mathrm{p}<0,05)$ (Tabela 1). A maior problemática quando se tem elevada carga microbiana no leite é que a atividade enzimática a partir de $1,0 \times 10^{4}$ UFC.mL ${ }^{-1}$ já é suficiente para comprometer as características do alimento, encurtando a sua vida útil (ZOCCHE et al., 2002).

A presença de bolores e leveduras nas amostras de leite variaram de 1,1 x $10^{4}$ a 3,3 x $10^{9}$ UFC. $\mathrm{mL}^{-1}$, sendo a maior contaminação observada nas amostras provenientes das padarias $(9,4 \mathrm{x}$ $10^{8}$ UFC.mL ${ }^{-1}$ ) (Tabela 1), embora sem diferença significativa $(\mathrm{P}<0,05)$ entre os estabelecimentos. Torkar e Vengust (2008), avaliando 60 amostras de leite in natura detectaram bolores e leveduras, respectivamente, em $95 \%$ e $63,3 \%$ das amostras. Apesar de não haver padrões microbiológicos na legislação brasileira para estes micro-organismos, a sua presença no leite representa riscos à saúde pública em virtude de algumas linhagens de fungos serem patogênicas ao homem.

A quantificação de coliformes a $35^{\circ} \mathrm{C}$ variou de 9,3 × $10^{2}$ a $>1,1 \times 10^{6} \mathrm{NMP} \cdot \mathrm{mL}^{-1}$ e a $45^{\circ} \mathrm{C}$ de 1,5 x $10^{1}$ a $>1,1 \times 10^{7}$ NMP. $\mathrm{mL}^{-1}$. Por estabelecimento, as amostras provenientes das padarias, foram estatisticamente significativas $(\mathrm{P}>0,05)$ em relação aos demais estabelecimentos (Tabela 1). Para os coliformes a $45^{\circ} \mathrm{C}$, houve variação de $2,0 \times 10^{4}$ a 1,0 x $10^{6}$ NMP.mL ${ }^{-1}$, sem diferença significativa entre os estabelecimentos, embora o leite comercializado nas padarias tenha sido o mais contaminado (Tabela 1). A presença de coliformes acima de $10^{3}$ NMP. $\mathrm{mL}^{-1}$ é considerado um indicativo de higiene deficitária na obtenção do produto, e elevada contagem de coliformes a $35^{\circ} \mathrm{C}$ no alimento pode 
indicar a presença de bactérias como Klebsiella, Serratia, Salmonella, Proteus, Citrobacter, dentre outras, responsáveis por causarem quadros de gastroenterites (CITADIN et al., 2009).

Escherichia coli foi encontrada em 76\% (19/25) nas amostras de leite. Apesar de E. coli não patogênica prevalecer no trato digestivo dos bovinos (LAVEN; ASHMORE; STEWART, 2003), sua presença no leite serve de indicador para a presença de bactérias patogênicas que alteram a qualidade do produto colocando em risco a saúde dos consumidores (LACERDA; MOTA; SENA., 2009).

As contagens de Staphylococcus spp. variaram de 1,0 × $10^{4}$ a $3,0 \times 10^{7}$ UFC.mL ${ }^{-1}$. Lamaita et al. (2005) relataram alta população de Staphylococcus spp. $\left(1,0 \times 10^{5}\right.$ a $2,5 \times 10^{7}$ UFC.mL $\left.\mathrm{mL}^{-1}\right)$ em leite in natura em Minas Gerais. Staphylococcus coagulase positiva foi identificado em $44 \%$ das amostras, sendo a maior média $\left(2,9 \times 10^{6}\right.$ UFC.mL $\left.L^{-1}\right)$ observada nas amostras de leite obtidas nos açougues (Tabela $1)$, com diferença significativa $(\mathrm{P}>0,05)$ entre os estabelecimentos. Esses dados corroboram com Maciel et al. (2008) ao relataram contagens de $S$. aureus na ordem de $10^{5}-10^{6}$ UFC. $\mathrm{mL}^{-1}$ em $33,3 \%$ do leite analisado. Nos açougues de Cruz das Almas as condições higiênicas-sanitárias foram as mais precárias, sendo visível a presença de insetos, restos de sangue dos animais abatidos, bem como a comercialização simultânea de carne e leite, além da manipulação de dinheiro. Embora o Ministério da Saúde não estabeleça padrão microbiológico para Staphylococcus coagulase positiva no leite in natura, a presença do patógeno nos alimentos a partir de 1,0 x $10^{5}$ UFC.mL - $^{-1}$ têm importância epidemiológica por propiciar intoxicação alimentar, sendo que 0,375 $\mu \mathrm{g}$ da enterotoxina estafilocócica/ $\mathrm{Kg}$ corpóreo é suficiente para causar um quadro de intoxicação (FRANCO; LANDGRAF, 2008).
Salmonella spp. não foi encontrada nas amostras de leite analisadas. Apesar da ausência de Salmonella nas amostras, a elevada carga microbiana no leite in natura ressalta falhas graves de higiene na obtenção, armazenamento, distribuição e comercialização do alimento (PINTO; MARTINS; VANETTI, 2006).

Nos estabelecimentos estudados, observou-se por diversas vezes a comercialização do leite em recipientes de plástico, muitos deles reutilizados e mal higienizados. O produto também foi encontrado armazenado em latões ou embalado em saco plástico de 1 litro à temperatura ambiente. Em alguns estabelecimentos não foi possível verificar a forma de armazenamento pelo fato do produto ficar armazenado fora do alcance dos consumidores.

Embora a comercialização do leite in natura seja legalmente proibida no país, à falta de fiscalização pelos órgãos competentes não tem impedido o mercado informal do alimento. O que se observa é a comercialização de um produto de má qualidade, que não oferece segurança aos consumidores. A falta de estrutura nas propriedades leiteiras no município de Cruz das Almas, sem um laticínio que possa receber o leite, faz com que os produtores comercializem o produto sem tratamento térmico, no comércio local ou diretamente com os consumidores.

Com relação ao perfil de suscetibilidade antimicrobiana, embora E. coli tenha apresentado mais de $80 \%$ de suscetibilidade aos antimicrobianos cloranfenicol, nitrofurantoina, amicacina, imipinem e ampicilina, a elevada resistência a tetraciclina $(57,9 \%)$ e resistência intermediária ao ácido nalidíxico $(36,8 \%)$, a gentamicina $(36,8 \%)$ e a cefalotina $(78,9 \%)$ (Figura 1 ) sugere o uso de antimicrobianos na alimentação animal, uma vez que a pressão seletiva exercida pelo uso intensivo dessas drogas tem reforçado o desenvolvimento de resistência aos micro-organismos (MANIE et al., 1998). 
Figura 1. Percentual de suscetibilidade antimicrobiana de Escherichia coli isoladas de amostras de leite in natura comercializado em Cruz das Almas, Bahia, durante o período de abril a setembro de 2010.

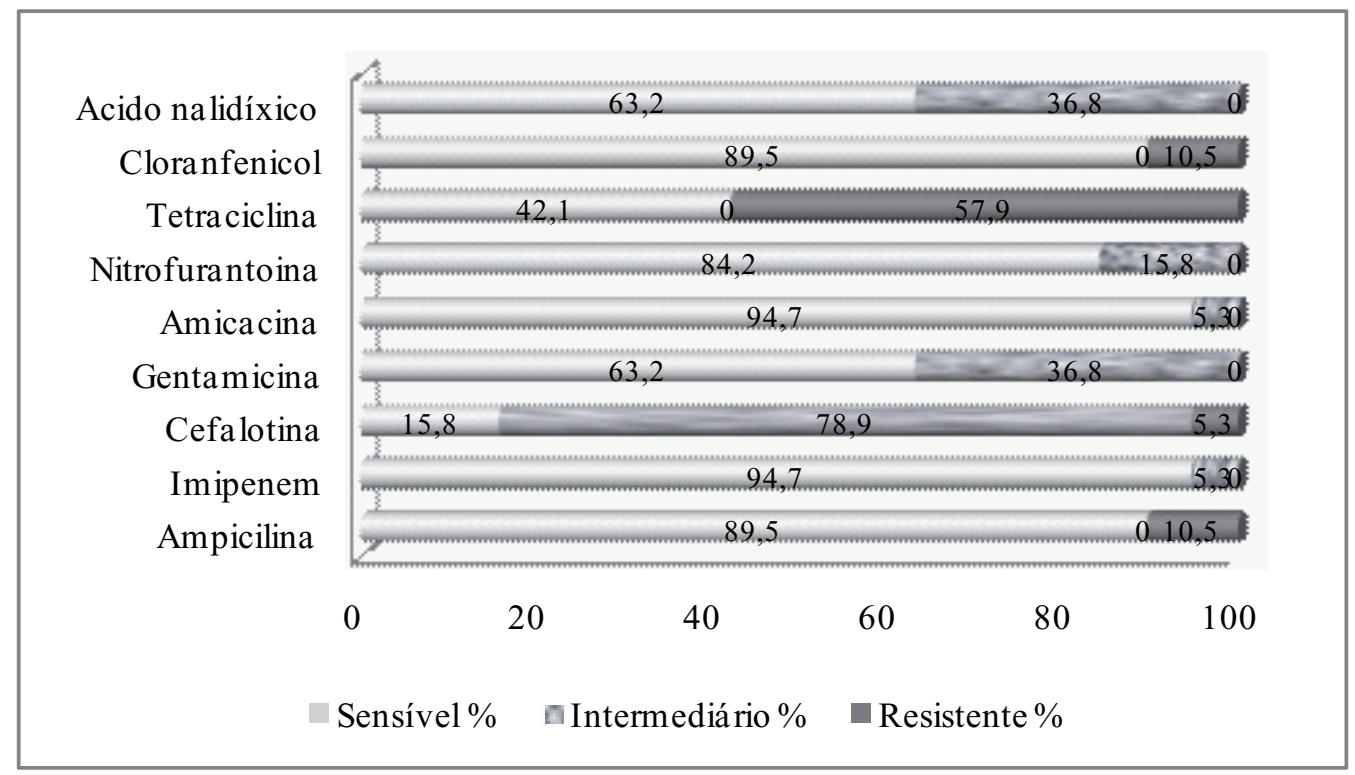

Fonte: Elaboração dos autores.

A resistência aos $\beta$-lactâmicos pode ocorrer em virtude de sua ampla utilização no tratamento de infecções no gado leiteiro e em vacas em lactação (COSTA, 2002). Tetzner et al. (2005) analisando amostras de leite cru na região do Triângulo Mineiro, MG observaram positividade para os betalactâmicos em 33,3\% das amostras. A legislação brasileira proibe o uso de promotores de crescimento como os anfenicóis, tetraciclinas, betalactâmicos (benzilpenicilâmicos e cefalosporinas), quinolonas e sulfonamidas sistêmicas (BRASIL, 2009). Apesar disso, tem-se observado cada vez mais um aumento no número de bactérias resistentes à tetraciclina (MOTA et al., 2005). O aumento da resistência à tetraciclina ocorre porque vários genes de resistência a esse antimicrobiano são transferidos as bactérias sensíveis através de plamideos ou outros elementos cromossômicos móveis após o evento de conjugação (MELVILLE et al., 2004). Desse modo, antimicrobianos usados na medicina veterinária promovem resistência cruzada com antimicrobianos utilizados na medicina humana, contribuindo para a aquisição de resistência de micro-organismos patógenos humanos (BIACCHI; JORGE; UENO, 2004). Carlos et al. (2004), avaliando o leite tipo "C" no município de Campos dos Goytacazes, RJ relataram que apenas em 07 (32,56\%) de 43 amostras de leite não foi detectado a presença de resíduo de penicilina.

Para as cepas de Staphylococcus coagulase positiva $100 \%$ de susceptibilidade foi observada para o sulfazotrim, ciprofloxacino, tetraciclina e ceftazidima (Figura 2). A elevada suscetibilidade antimicrobiana em Staphylococcus coagulase positiva, principal agente responsável por causar mastite no rebanho leiteiro, é satisfatória, embora não se possa afirmar se esses micro-organismos presentes no leite foram provenientes do rebanho leiteiro ou dos produtores ou manipuladores em virtude de falhas higiênicas-sanitárias. 
Figura 2. Percentual de suscetibilidade antimicrobiana de Staphylococcus coagulase positiva isolados de amostras de leite in natura comercializado em Cruz das Almas, Bahia, durante o período de abril a setembro de 2010.

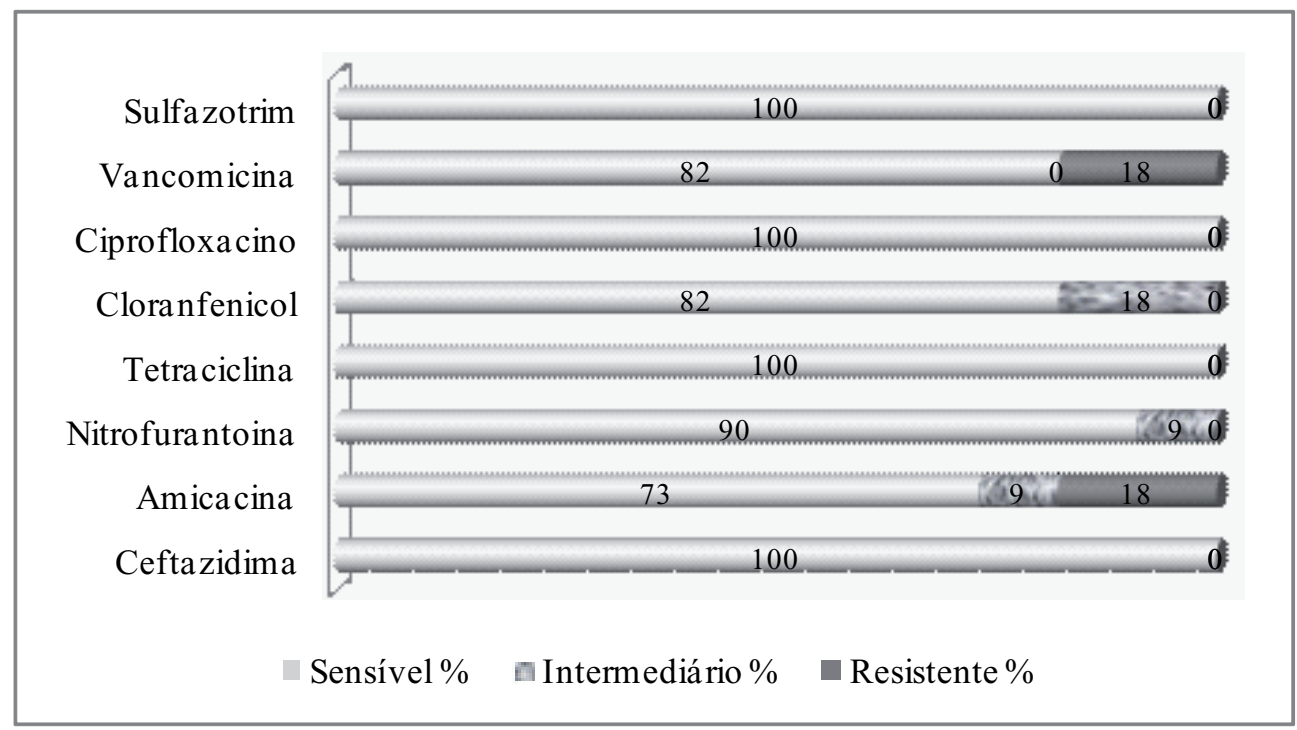

Fonte: Elaboração dos autores.

Segundo Colli, Pizzolitto e Raddi (2009) a vigilância dos padrões de sensibilidade aos antimicrobianos para $S$. aureus é importante para a compreensão das tendências emergentes de resistência. Enquanto o melhoramento nos métodos de manejo animal, introdução de programas de vacinação e a elaboração de uma legislação que regulasse o uso de antimicrobianos na veterinária, poderia promover a suspensão dos antimicrobianos como promotores de crescimento na alimentação animal (VAN DEN BOGAARD; STOBBERINGH, 2000).

As estirpes de Staphylococcus coagulase positiva apresentaram resistência à vancomicina e a amicacina em 18\% (Figura 2). A resistência adquirida as quinolonas tem ocorrido há algumas décadas e por isso, a vancomicina tornou-se uma das últimas opções terapêuticas contra bactérias multirresistentes, o que fez com que sua aplicação na medicina veterinária fosse proibida (CRUZ, 2009). De ação bactericida, essa droga atua contra bactérias Gram-positivas, impedindo a síntese da parede celular bacteriana pela inibição da liberação de um polímero da membrana celular (ANDRADE, 2002). Pontes Netto et al. (2005) observaram que os aminoglicosídeos foram o segundo maior grupo de antimicrobianos usados na terapêutica do gado leiteiro no Paraná, Brasil no período de 2003.

Sete estirpes de E. coli apresentaram índice MAR igual a 22\%, ou seja, resistência a dois antimicrobianos, enquanto para Staphylococcus coagulase positiva, o índice foi de $12,5 \%$, sem perfil de multiressistência (Tabela 2). Nascimento, Maestro e Campos (2001) testando bactérias patogênicas isoladas de leite em Piracicaba, SP, relataram resistência múltipla de $27 \%$ para os coliformes e 3\% para Staphylococcus aureus. Para o autor, apesar da legislação regulamentar a presença de resíduos de antibióticos no leite, os produtores não têm o rigor de cumpri-las e nem a fiscalização vigente dos órgãos competentes pode garantir a segurança dos alimentos, tanto do leite quanto de seus derivados. 
Tabela 2. Indice de múltipla resistência a antimicrobianos (MAR) e perfil de resistência plasmidial de Escherichia coli e Staphylococcus coagulase positiva isolados de leite in natura, obtido no comercio varejista de Cruz das Almas, Bahia, durante o período de abril a setembro de 2010.

\begin{tabular}{cccc}
\hline Cepa & Antimicrobianos & MAR (\%) & Resistência Plasmidial \\
\hline Ec 2 & TET - CFL & 22,22 & - \\
Ec 7 & AMP - TET & 22,22 & AMP - TET \\
Ec 8 & TET & 22,22 & TET \\
Ec 9 & TET & 11,11 & - \\
Ec 11 & TET & 11,11 & - \\
Ec 12 & TET & 11,11 & - \\
Ec 13 & TET & 11,11 & - \\
Ec 14 & AMP - TET & 22,22 & - \\
Ec 17 & TET & 22,22 & TET \\
Ec 18 & CLO - TET & 22,22 & CLO - TET \\
Ec 19 & CLO - TET & 22,22 & - \\
Sc +10 & AMI & 12,5 & - \\
Sc +23 & VAN & 12,5 & - \\
Sc +25 & AMI & 12,5 & - \\
\hline
\end{tabular}

$\mathrm{Ec}=$ E. coli $; \mathrm{Sc}+=$ Staphylococcus coagulase positiva.

$\mathrm{TET}=$ tetraciclina; $\mathrm{AMP}=$ ampicilina $; \mathrm{CFL}=$ cloranfenicol; $\mathrm{VAN}=$ vancomicina; $\mathrm{AMI}=$ amicacina.

Fonte: Elaboração dos autores.

Perfil de multirresistência mediada por plasmidio foi observado em $57 \%$ das estirpes de $E$. coli (Tabela 2). Os plasmídios contêm genes de resistência que podem se replicar independentemente do cromossomo hospedeiro, sendo distinguidos por sua origem e repetição, onde uma única bactéria pode abrigar múltiplos plasmídios (ALEKSHUN; LEVY, 2007). Já para a resistência cromossômica os genes são transferidos com frequência relativamente baixa e o seu impacto clínico é menor que o da resistência plasmidial (SILVA, et al., 2009).

O aumento da resistência está relacionado ao uso abusivo de antibimicrobianos, embora atualmente os órgãos competentes venham tentando controlar mais efetivamente a utilização dessas drogas pela população. Segundo Freitas et al. (2004) os antimicrobianos têm ação destrutiva nas células bacterianas, e o surgimento de resistência múltipla aos antibióticos, representa um risco potencial à saúde publica podendo dificultar o tratamento de doenças humanas e animais, agravando quadros clínicos potencialmente curáveis.
$\mathrm{O}$ leite in natura comercializado em Cruz das Almas apresenta elevada carga microbiana, podendo servir de veículo para surtos de toxiinfecções alimentares. Por outro lado, o perfil de resistência a gentamicina e vancomicina nas estirpes de Staphylococcus coagulase positiva e multirresistência nas cepas de E. coli demonstram o risco potencial na disseminação de micro-organismos resistentes a diversas drogas à população usuária do alimento, na ausência de tratamento térmico.

\section{Referências}

ALEKSHUN, M. N.; LEVY, B. S. Molecular mechanisms of antibacterial multidrug resistance. Cell, Massachusetts, v. 128, n.6, p. 1037-1050, 2007.

ALMEIDA, L. P.; VIEIRA, R. L.; ROSSI, D. A.; CARNEIRO, A. L.; ROCHA, M. L. Antibiotic residues in milk of rural properties of Uberlândia - MG region. Bioscience Journal, Uberlandia, v. 19, n. 3, p. 83-87, 2003.

ALVES, L. M. C.; AMARAL, L. A.; CORRÊA, M. R.; SALES, S. S. Qualidade microbiológica do leite cru e de queijo de coalho comercializados informalmente na cidade de são Luís - Ma. Pesquisa em Foco, São Luis, v. 17, n. 2, p. 1-13, 2009. 
ANDRADE, S. P. Manual de terapêutica veterinária. 2. ed. São Paulo: Rocca, 2002. 697 p.

BIACCHI, N. C.; JORGE, A. O. C.; UENO, M. Detection of antibiotics residues in cow milk in Vale do Paraíba, São Paulo. Revista Biociências, Taubaté, v. 10, n. 1, p. 47-49, 2004.

ARCURI, E. F.; BRITO, M. A. V. P.; BRITO, J. R. F.; PINTO, S. M.; ÂNGElO, F. G. F.; SOUZA, G. N. Qualidade microbiológica do leite refrigerado nas fazendas. Arquivo Brasileiro de Medicina Veterinária e Zootecnia, Belo Horizonte, v. 58, n. 3, p. 440-446, 2006.

BRASIL. Ministério da Agricultura, Pecuária e Abastecimento. Instrução normativa no26 de 09 de julho de 2009. Aprova o Regulamento técnico para a fabricação, o controle de qualidade, a comercialização e o emprego de produtos antimicrobianos de uso veterinário. Diário Oficial [da] União, Brasília, DF, 10 jul. 2009. seção 1, p. 14.

Ministério da Agricultura e do Abastecimento. Secretaria de Defesa Agropecuária. Instrução Normativa $\mathrm{n}^{\circ} 62$ de 29 de dezembro de 2011. (Regulamento Técnico de Produção, identidade, qualidade, coleta e transporte do leite). Diário Oficial [da] União, Brasília, DF, 30 dez. 2011. seção 1, p. 6.

CARLOS, L. A.; CORDEIRO, C. A. M.; FOLLY, M. M.; MARTINS, M. L. L. Avaliação físico-química, microbiológica e de resíduos de penicilina, em leite tipo "C" comercializado no município de Campos dos Goytacazes, RJ. Higiene Alimentar, São Paulo, v. 18, n. 123, p. 57-60, 2004.

CITADIN, A. S.; POZZA, M. S. S.; POZZA, P. C.; NUNES, R. V.; BORSATTI, L.; MANGONI, J. Microbiological quality of raw milk and factors that influence its quality. Revista Brasileira de Saúde e Produção Animal, Salvador, v. 10, n.1, p. 52-59, 2009.

CLINICALLABORATORY STANDARDS INSTITUTE - CLSI. Performance Standards for antimicrobial susceptibility testing. Twentieth Informational Supplement, M100-S20. Wayne, PA: CLSI, 2005.

COLLI, V. C.; PIZZOLITTO, A. C.; RADDI, M. S. G. Determinação da resistência de Staphylococcus aureus: um desafio? Revista de Ciências Farmacêuticas Básica e Aplicada, Araraquara, v. 30, n. 1, p. 115-118, 2009.

COSTA, E. O. Uso de antimicrobianos na mastite. In: SPINOSA, H. S.; GÓRNIAK, S. L.; BERNARDI, M. M. (Ed.). Farmacologia aplicada à medicina veterinária. 3. ed. Rio de Janeiro: Guanabara Koogan, 2002. p. 443-455.

CRUZ, A. R. Perfil de sensibilidade de bactérias patogênicas isoladas de cães frente a antimicrobianos.
2009. Dissertação (Mestrado em Bacteriologia Veterinária) - Faculdade de Medicina Veterinária e Zootecnia. Universidade Estadual Paulista, Botucatu.

EMPRESA BRASILEIRA DE AGROPECUÁRIA EMBRAPA. Estatísticas do leite: produção total de leite, sob inspeção e vacas ordenhadas no Brasil. Disponível em: <http://www.cnpgl.embrapa.br/nova/informacoes/ estatisticas/producao/tabela0231.php.> Acesso em: 20 nov. 2012.

MACIEL, J. F.; CARVALHO, E. A.; SANTOS, L. S.; ARAUJO, J. B.; NUNES, V. S. Microbiological quality of raw milk marketed in Itapetinga-BA. Revista Brasileira de Saúde e Produção Animal, Salvador, v. 9, n. 3, p. 443-448, 2008.

FRANCO, B. D. G. M.; LANDGRAF, M. Microbiologia dos alimentos. São Paulo: Atheneu, 2008. 182 p.

FREITAS, M. F. L.; MOTA, R. A.; LEÃO, A. E. D. S.; FIGUEIREDO, M. L.; FONTE, M. M.; VIEIRA, R. F. C. Sensibilidade antimicrobiana de cepas de Staphylococcus spp isoladas de carcaças de frango comercializadas em Recife. Arquivo Brasileiro de Medicina Veterinaria e Zootecnia, Belo Horizonte, v. 56, n. 3, p. 405-407, 2004.

GERMANO, P. M. L.; GERMANO, M. I. S. Higiene e vigilância sanitária de alimentos. 3. ed. São Paulo: Manole, 2008. 986 p.

HIRSCH, D.; PEREIRA JUNIOR, D. J.; LOGATO, P. V. R.; PICCOLI, R. H.; FIGUEIREDO, H. C. P. Identification and antimicrobial resistance of motile Aeromonas isolated from fish and aquatic environment. Ciência Agrotécnica, Lavras, v. 30, n. 6, p. 1211-1217, 2006.

LACERDA, L. M.; MOTA, R. A.; SENA, M. J. Qualidade microbiológica da água utilizada em fazendas leiteiras para limpeza das tetas de vacas e equipamentos leiteiros em três municípios do Estado do Maranhão. Arquivo do Instituto Biológico, São Paulo, v. 76, n. 4, p. 569-575, 2009.

LAMAITA, H. C.; CERQUEIRA, M. M. O. P.; CARMO, L. S.; SANTOS, D. A.; PENNA, C. F. A. M.; SOUZA, M. R. Staphylococcus sp. counting and detection of staphylococcal enterotoxins and toxic shock toxin syndrome from cooled raw milk. Arquivo Brasileiro de Medicina Veterinaria e Zootecnia, Belo Horizonte, v. 57, n. 5, p. 702-709, 2005.

LAVEN, R. A.; ASHMORE, A.; STEWART, C. S. Escherichia coli in the rumen and colon of slaughter cattle, with particular reference to E. coli O157. The Veterinary Journal, London, v. 165, n. 1, p. 78-83, 2003. 
MANIE, T.; KHAN, S.; BROZEL, V. S.; VEITH, W. J.; GOUWS, P. A. Antimicrobial resistence of bacteria isolated from slaughtered and retail chickens in south Africa. Letters in Applied Microbiology, Oxford, v. 26, n. 4, p. 253-258, 1998.

MELO, B. A.; SANTOS, T. M. C.; BARBOSA, Y. R. S.; MOURA, C. T. R.; MONTALDO, Y. C. Aspectos microbiológicos de amostras de leite cru coletadas no município de Major Isidoro - Alagoas. Revista Verde, Mossoró, v. 5, n. 5, p. 1-5, 2010.

MELVILLE, C. M.; SCOTT, K. P.; MERCER, D. K.; FLINT, H. J. The Butyrivibrio fibrisolvens tet (W) gene is carried on the novel conjugative transposon TnB1230 which contains duplicated nitroreductase coding sequences. Journal of Bacteriology, Washington, v. 186, n. 11, p. 3656-3659, 2004.

MOLINA-AJA, A.; GARCÍA-GASCA, A.; ABREUGROBOIS, A.; BOLAN-MEJIA, C.; ROQUE, A.; GOMEZ-GIL, B. Plasmid profiling and antibiotic resistance of Vibrio strains isolated from cultured penaeid shrimp. FEMS Microbiology Letters, Amsterdam, v. 213, n. 1, p. 7-12, 2002.

MOTA, A. M.; SILVA, K. P. C.; FREITAS, M. F. L.; PORTO, W. J. N.; SILVA, L. B. G. The abuse of antimicrobials drugs and the appearance of resistance. Brazilian Journal of Veterinary Research and Animal Science, São Paulo, v. 42, n. 6, p. 465-470, 2005.

NASCIMENTO, G. G. F.; MAESTRO, V.; CAMPOS, M. S. P. Ocorrências de resíduos de antibióticos no leite comercializado em Piracicaba, São Paulo, Brasil.2001. Brazilian Journal of Nutrition, Campinas, v. 14, n. 2, p. 119-124, 2001.

NERO, L. A.; VIÇOSA, G. N.; PEREIRA, F. E. V. Qualidade microbiológica do leite determinada por características de produção. Ciência e Tecnologia de Alimentos, Campinas, v. 29, n. 2, p. 386-390, 2009.

PINTO, C. L. O.; MARTINS, M. L.; VANETTI, M. C. D. Qualidade microbiológica de leite cru refrigerado e isolamento de bactérias psicrotróficas proteolíticas. Ciência e Tecnologia de Alimentos, Campinas, v. 26, n. 3, p. 645-651, 2006.

PONTES NETO, D.; LOPES, M. O.; OLIVEIRA, M. C. S.; NUNES, M. P.; MACHINSJI JR, M.; BOSQUIROLI, S. L.; BENATTO, A.; BOMBARDELLI, A. L. C.; VEDOVELLO FILHO, D. Levantamento dos principais fármacos utilizados no rebanho leiteiro do Estado do Paraná. Acta Scientiarum Animal Sciences, Maringá, v. 27, n. 1, p. 105-111, 2005.
SANTANA, E. H. W.; BELOTI, V.; BARROS, M. A. F.; MORAES, L. B.; GUSMÃO, V. V.; PEREIRA, M. S. Milk contamination in different points of the process: I) Aerobic mesophilics and psychrotrophics microorganisms. Semina: Ciências Agrárias, Londrina, v. 22, n. 2, p. 145-154, 2001.

SCHEDLER, C. A.; POZZA, M. S. S.; POZZA, P. C.; NUNES, R. V.; BORSATTI, L.; MANGONI, J. Microbiological quality of raw milk and factors that influence its quality. Revista Brasileira de Saúde e Produção Animal, Salvador, v. 10, n. 1, p. 52-59, 2009.

SILVA, N.; JUNQUEIRA, V. C. A.; SILVEIRA, N. F. A.; TANIWAKI, M. H.; SANTOS, R. F. S.; GOMES, R.A.R. Manual de métodos de análise microbiológica de alimentos. 3. ed. São Paulo: Varela, 2007. 536 p.

SILVA, N. S.; OLIVERIA, A. C.; CANESINI, R.; ROCHA, J. R.; PERREIRA, R. E. P. Mecanismos de resistência bacteriana. Revista Científica Eletrônica de Medicina Veterinária, Garça, ano 7, v. 12, p.1-4, 2009. Disponível em: $<$ http://www.revista.inf.br/veterinaria12/ revisao/pdf/AnoVII-Edic12-Rev101.pdf $>$. Acesso em: 14 nov. 2012.

TETZNER, T. A. D.; BENEDETTI, E.; GUIMARÃES, E. C.; PERES, R. F. G. Prevalência de resíduos de antibióticos em amostras de leite cru na região do Triângulo Mineiro. Higiene Alimentar, São Paulo, v. 19, n. 130, p. 69-72, 2005.

TORKAR, K. G.; VENGUST, A. The presence of yeasts, moulds and aflatoxin M-1 in raw milk and cheese in Slovenia. Food Control, Guildford, v. 19, n. 6, p. 570577, 2008.

VAN DEN BOGAARD, A. E.; STOBBERINGH, E. E. Epidemiology of resistance to antibiotics links between animals and humans. International Journal of Antimicrobial Agents, Philadelphia, v. 14, n. 4, p. $327-$ 335,2000 .

ZOCCHE, F.; BERSOT, L. S.; BARCELLOS, V. C.; PARANHOS, J. K.; ROSA, S. T. M.; RAYMUNDO, N. K. Qualidade microbiológica e físico-química do leite pasteurizado tipo produzido na região oeste do Paraná. Archives of Veterinary Science, Curitiba, v. 7, n. 2, p. 5967, 2002. 
